\title{
Sex differences in brain aromatase activity: genomic and non-genomic controls
}

\section{Jacques Balthazart ${ }^{1}$, , Thierry D. Charlier ${ }^{1}$, Charlotte A. Cornil ${ }^{1}$, Molly J. Dickens ${ }^{1}$, Nobuhiro Harada ${ }^{2}$, Anne T. M. Konkle ${ }^{1+}$, Cornelia Voigt ${ }^{1 \dagger}$ and Gregory F. Ball ${ }^{3}$}

${ }^{1}$ Groupe Interdisciplinaire de Génoprotéomique Appliquée Neurosciences, University of Liege, Liege, Belgium

${ }^{2}$ Molecular Genetics, Fujita Health University, Toyoake, Aichi, Japan

${ }^{3}$ Department of Psychological and Brain Science, Johns Hopkins University, Baltimore, MD, USA

\section{Edited by:}

Hubert Vaudry, University of Rouen,

France

\section{Reviewed by:}

Victor M. Navarro, University of

Córdoba, Spain

Raphael Pinaud, University of

Oklahoma Health Sciences Center,

USA

Giancarlo Panzica, Universita' di

Torino, Italy

\section{*Correspondence:}

Jacques Balthazart, Research Group

in Behavioral Neuroendocrinology,

Groupe Interdisciplinaire de

Génoprotéomique Appliquée

Neurosciences, University of Liège,

Avenue de I'Hopital, 1 (BAT. B36),

B-4000 Liège 1, Belgium.

e-mail: jbalthazart@ulg.ac.be

${ }^{t}$ Present address:

Anne T. M. Konkle, Interdisciplinary School of Health Sciences, University of Ottawa, Ottawa, ON, Canada; Cornelia Voigt, Max Planck Institute for Ornithology, 82319 Seewiesen, Germany.
Aromatization of testosterone into estradiol in the preoptic area plays a critical role in the activation of male copulation in quail and in many other vertebrate species. Aromatase expression in quail and in other birds is higher than in rodents and other mammals, which has facilitated the study of the controls and functions of this enzyme. Over relatively long time periods (days to months), brain aromatase activity (AA), and transcription are markedly (four- to sixfold) increased by genomic actions of sex steroids. Initial work indicated that the preoptic AA is higher in males than in females and it was hypothesized that this differential production of estrogen could be a critical factor responsible for the lack of behavioral activation in females. Subsequent studies revealed, however, that this enzymatic sex difference might contribute but is not sufficient to explain the sex difference in behavior. Studies of AA, immunoreactivity, and mRNA concentrations revealed that sex differences observed when measuring enzymatic activity are not necessarily observed when one measures mRNA concentrations. Discrepancies potentially reflect post-translational controls of the enzymatic activity. AA in quail brain homogenates is rapidly inhibited by phosphorylation processes. Similar rapid inhibitions occur in hypothalamic explants maintained in vitro and exposed to agents affecting intracellular calcium concentrations or to glutamate agonists. Rapid changes in AA have also been observed in vivo following sexual interactions or exposure to short-term restraint stress and these rapid changes in estrogen production modulate expression of male sexual behaviors. These data suggest that brain estrogens display most if not all characteristics of neuromodulators if not neurotransmitters. Many questions remain however concerning the mechanisms controlling these rapid changes in estrogen production and their behavioral significance.

Keywords: aromatase, sex differences, Japanese quail, preoptic area, phosphorylations, immunohistochemistry, in situ hybridization, non-genomic control

\section{INTRODUCTION}

The sex steroid testosterone $(\mathrm{T})$ plays a critical role in the activation of male sexual behavior in nearly all vertebrate species investigated to this date. It was thought for many years that this behavioral activation was directly related to the production of this steroid hormone by the testes. However, discrepancies between circulating concentrations of $\mathrm{T}$ and behavioral activity have forced scientists to reconsider this notion (Ball and Balthazart, 2008). It has now become clear that behavioral effects of $\mathrm{T}$ results from the more or less independent regulation of $\mathrm{T}$ synthesis and action at several different levels in this physiological process. This independent and differential regulation of $\mathrm{T}$ provides some possible explanations of these discrepancies between plasma $\mathrm{T}$ concentrations and behavior. To exert its behavioral effects, $\mathrm{T}$ must first reach the brain, it must then eventually be metabolized into more or less active metabolites, bind to specific receptors, and regulate either the transcription of specific genes (genomic effects) or modulate the activity of a variety of intracellular signaling pathways (non-genomic effects; Ball and Balthazart, 2002, 2008).
Each of these steps is potentially modulated by independent control mechanisms (Charlier, 2009). For example, access of steroids to the brain can be influenced by the concentration of binding proteins present in the plasma (Hammond, 1995; Deviche et al., 2001; Breuner et al., 2006). In addition, receptor concentrations can vary independently of the concentration of the ligand and their transcriptional activity is markedly affected by the presence of a whole family of proteins known as co-regulators that enhance (coactivators) or inhibit (co-repressors) transcription (O'Malley and Tsai, 1992; Smith and O'Malley, 2004; Tetel et al., 2009). All these processes potentially affect steroid actions in the brain without changing their concentration in the plasma.

A substantial body of research has also been dedicated to the intracellular metabolism of $\mathrm{T}$ and its implication in the control of the behavioral effects of this steroid (McEwen, 1981; Balthazart, 1989). One particular aspect of this metabolism that has received a lot of attention is the transformation of androgens, such as $T$ into estrogens such as estradiol- $17 \beta$, a process catalyzed by the enzyme aromatase. It was discovered around the middle of the 
Twentieth century that many behavioral and physiological effects of T could be reproduced by injections of estradiol (Beach, 1948). A plausible explanation for this seemingly paradoxical finding was provided when it was discovered that $\mathrm{T}$ can actually be transformed into estradiol in the brain of mammals including humans (Naftolin et al., 1972, 1975), a finding that was soon extended to all classes of vertebrates (Callard et al., 1978a,b). Our laboratory has investigated this aromatization process, its control, and functional significance, in one avian species, the Japanese quail (Coturnix japonica) for now more than 25 years. In this review, we would like to (1) briefly summarize the evidence demonstrating that brain aromatization of $\mathrm{T}$ plays a key limiting role in the activation of sexual behavior in male quail, (2) describe the mechanisms that control the activity of this critical enzyme in the male brain, and finally (3) describe in more detail recent studies that have analyzed the mechanisms controlling the prominent sex difference affecting the activity of this brain enzyme. The first two topics have already been reviewed relatively recently (Balthazart, 1989; Balthazart and Foidart, 1993; Balthazart et al., 2004, 2009b; Balthazart and Ball, 2006) and will therefore be summarized here only briefly. The focus of this presentation will be on the sex differences affecting these processes since these were investigated and published much more recently.

\section{BRAIN AROMATASE AND THE CONTROL OF MALE SEXUAL BEHAVIOR IN QUAIL}

In quail like in many other species of birds and mammals, the activation of male copulatory behavior by $\mathrm{T}$ requires the aromatization of this androgenic steroid into an estrogen. This conclusion is supported by a variety of converging experimental data collected over almost 30 years based primarily on four types of experimental procedures:

(a) Aromatizable androgens such as T or androstenedione activate male sexual behavior in castrates, whereas non-aromatizable androgens such as $5 \alpha$-dihydrotestosterone (DHT) or methyltrienolone (R1881) have little or no effect (Adkins, 1977; Adkins et al., 1980; Balthazart et al., 1985),

(b) Behavioral effects of $\mathrm{T}$ on sexual behavior in castrated quail can be mimicked by estrogens such as estradiol or by synthetic estrogenic compounds such as diethylstilbestrol (Adkins and Pniewski, 1978; Adkins et al., 1980; Schumacher and Balthazart, 1983; Alexandre and Balthazart, 1986),

(c) Aromatase inhibitors such as androstatrienedione (ATD), 4hydroxyandrostenedione (4OHA), Fadrozole, or Vorozole (or R76713) markedly inhibit or block the activation of male sexual behavior by exogenous T (Adkins et al., 1980; Balthazart et al., 1990a; Foidart et al., 1994b). Some experiments also showed that these behavioral effects of aromatase inhibitors are reversed by the concurrent administration of an estrogen (e.g., Adkins et al., 1980). This demonstrates that effects of aromatase inhibition are specific to the estrogen depletion and do not result from non-specific toxic effects of the drugs.

(d) Finally, the injection of antiestrogens (tamoxifen or nitromifene citrate, also known as CI-628) that block the access of estrogens to their specific receptors block T-induced sexual behavior (Adkins and Nock, 1976; Alexandre and Balthazart,
1986). A large body of evidence thus supports the idea that, in quail, the action of $\mathrm{T}$ on male sexual behavior requires its aromatization into an estrogen (the aromatization hypothesis; Yahr, 1979) followed by the binding of these estrogenic metabolites of $\mathrm{T}$ to estrogen receptors.

The preoptic area and more specifically the sexually dimorphic medial preoptic nucleus (POM) is a critical site of $\mathrm{T}$ aromatization and estrogen action in relation to the activation of male copulatory behavior in quail (Panzica et al., 1996; Balthazart and Ball, 2007). This has been demonstrated by experiments showing that stereotaxic implantation of aromatase inhibitors or of antiestrogens within the POM but not in adjacent brain areas blocks the activation of sexual behavior by peripheral treatment with exogenous T (Balthazart and Surlemont, 1990).

It should be remembered that all the evidence summarized above does not exclude an additional subsidiary but nevertheless significant, contribution of $\mathrm{T}$ itself or of its androgenic metabolites (e.g., DHT) to the activation of male sexual behavior in quail (see Balthazart, 1989; Balthazart et al., 2004 for a detailed summary of the data supporting this notion). The mechanisms by which androgens and estrogens synergize to activate behavior are still not fully understood. Such mechanisms might involve (1) the interaction of both classes of steroids with their specific receptors located in the same neurons or in different neurons belonging to a same functional circuitry, (2) their action on parallel circuits that finally converge to activate the behavior, (3) their action at different loci in the organism (e.g., action of estradiol in the brain and of DHT on peripheral structures such as the penis in mammals or the cloacal gland area in quail), or (4) an inhibitory action of estradiol on DHT catabolism into less active diols (see Ball and Balthazart, 2002 for additional discussion of this topic).

It is also useful to note here that all effects of estrogens on brain and behavior are not necessarily mediated by their interaction with intracellular estrogen receptors. A growing number of effects of estrogens on neuronal membranes have been described in the last few decades and they appear to be relevant to the control of male sexual behavior. A detailed discussion of the relevant evidence is however beyond the scope of the present review (see Cornil et al., 2006a; Cornil, 2009 for more information especially as it relates to the control of behavior in quail).

\section{CONTROL OF BRAIN AROMATASE ACTIVITY BY SEX STEROIDS}

Due to the critical importance of $\mathrm{T}$ aromatization as a limiting step for the activation of male copulatory behavior, an extensive amount of the research has been carried out in order to understand the mechanisms that control preoptic aromatase activity (AA). It was originally discovered in ring doves (Streptopelia risoria) that $\mathrm{T}$ markedly increases brain AA (Steimer and Hutchison, 1981) and this finding was later confirmed in a variety of avian and some mammalian species (Roselli and Resko, 1984, 1989; Schumacher and Balthazart, 1986). Our first study of brain AA in quail confirmed the major induction of this enzyme activity in the entire preoptic area and hypothalamus following $\mathrm{T}$ treatment of castrated males and showed that 
gonadectomy reduces the preoptic AA to basal levels (Schumacher and Balthazart, 1986).

Subsequent studies analyzed the specific localization of this effect of T by combining a sensitive radio-enzymatic assay of AA with a dissection of specific brain nuclei by the Palkovits punch technique (Palkovits and Brownstein, 1983; Schumacher and Balthazart, 1987). This indicated that effects of T on AA (decrease following castration and increase after treatment with $\mathrm{T}$ ) were particularly prominent in the POM but also present and statistically significant in hypothalamic nuclei such as the ventro-medial nucleus (VMN) or the tuberal region (Balthazart et al., 1990e).

This study still left a large degree of uncertainty concerning the localization of aromatase in the brain. However, in the early 1990s, an immunocytochemical technique was developed that allows the visualization of the aromatase protein at the cellular level in the quail brain using an antibody raised against purified human placental aromatase (Balthazart et al., 1990b,d). A few years later, quail aromatase was partly cloned (Harada et al., 1992), and a homologous antibody was produced against a recombinant aromatase antigen expressed in $E$. coli based on the isolated quail cDNA (Foidart et al., 1995). Analysis of brain aromatase with these antibodies indicated that, in quail, aromatase-immunoreactive (ARO-ir) material is found in specialized neurons that are clustered in a few brain nuclei including the POM, the medial part of the bed nucleus striae terminalis (BSTM), the VMN of the hypothalamus, and the nucleus taeniae of the amygdala (Balthazart et al., 1990b,d; Foidart et al., 1995). Interestingly, in the preoptic area, almost all ARO-ir neurons are located within the boundaries of the POM and their high density precisely defines the boundaries of the nucleus in agreement with the boundaries defined based on Nissl-stained material.

Based on the partial quail aromatase sequence, it also became possible to design specific riboprobes and investigate the neuroanatomical distribution of the aromatase mRNA by in situ hybridization histochemistry. The distribution of the message was then compared with the distribution of the protein, visualized by immunocytochemistry, and a nearly complete overlap was identified (Aste et al., 1998a).

Studies were then performed to quantify in a variety of physiological conditions the number of ARO-ir cells in the POM as well as the amount of aromatase mRNA as assessed either by polymerase chain reaction on the entire preoptic area-hypothalamus or by in situ hybridization (measure of the volume occupied by dense aromatase mRNA at the level of POM and of the optical density of this signal).

When considered as a whole, this work indicates that a chronic treatment of castrated male quail with exogenous $\mathrm{T}$ significantly increases AA as well as the number of ARO-ir neurons in the POM and the aromatase mRNA concentration measured by RT-PCR (see Figure 1; Balthazart and Foidart, 1993). This suggests that the control by $\mathrm{T}$ of AA takes place largely at the pretranslational (presumably transcriptional) level. The observed increase in AA is, however, slightly higher (sixfold) than the increase in the number of immunoreactive cells (fivefold), which is itself larger than the increase in the concentration of ARO mRNA (fourfold). There are two possible explanations for these differences: either they reflect different experimental errors associated with the different

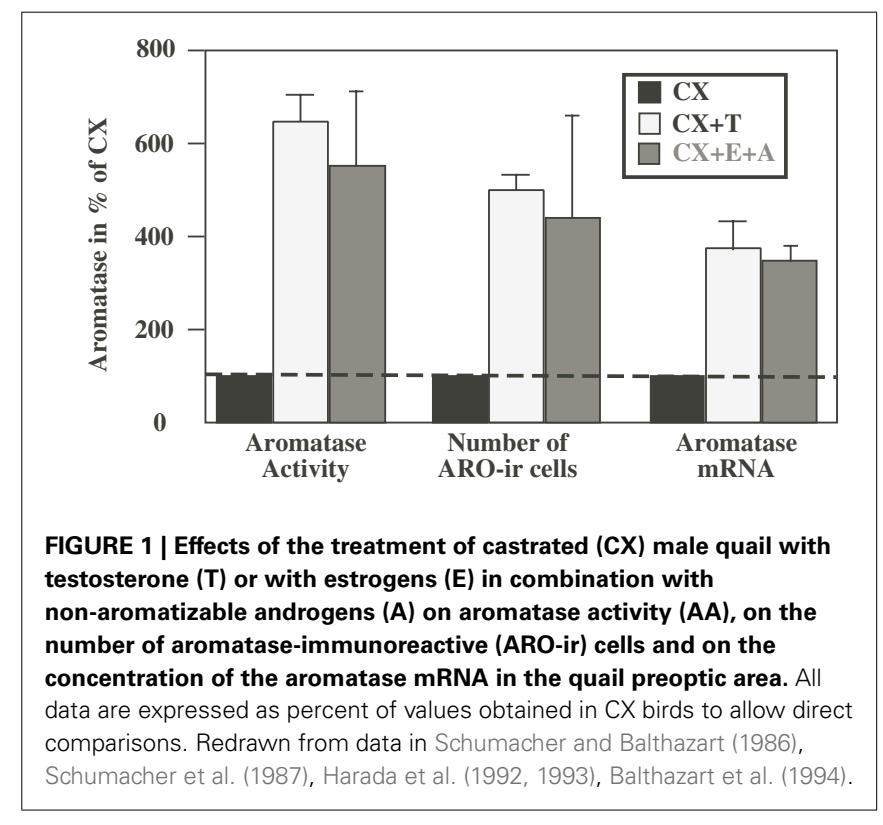

quantification techniques or they indicate that, $\mathrm{T}$ also affects the activity of the enzyme itself by mechanisms that do not depend on changes in enzyme transcription (modulation of the translation of existing mRNA molecules into protein and of the activity of the enzymatic protein.). This question will be revisited in the following section.

Interestingly, the effects of T on AA appear to be mostly mediated by the interaction of the steroid with androgen receptors in rats (Roselli and Resko, 1984; Roselli et al., 1987), and in contrast by an action of locally produced estrogens in birds (Hutchison and Steimer, 1986). In most species that were studied so far (Hutchison and Steimer, 1986; Roselli et al., 1987; Roselli, 1991) including quail, there is, however, as is the case for the activation of sexual behavior, a clear synergism between non-aromatizable androgens and estrogens in the mechanism that regulates aromatase. This synergism has been observed in quail at the three different levels at which aromatase could be studied: the mRNA concentration, the protein as assessed semi-quantitatively by immunocytochemistry and the enzyme activity (Schumacher et al., 1987; Harada et al., 1993; Balthazart et al., 1994; see Absil et al., 2001 for a summary of these data).

\section{RAPID NON-GENOMIC CONTROLS OF BRAIN AROMATASE ACTIVITY IN MALE QUAIL}

Although T-induced increases in preoptic AA are paralleled by changes in enzyme concentration that are largely mediated by the transcriptional action of the steroid, the apparent magnitude of this effect increases with the progression from DNA transcription to enzyme activity, suggesting that $\mathrm{T}$ may also regulate enzymatic activity by other means. Indeed, recent work has identified changes in AA that are much too fast (within minutes) to be possibly have occurred based on a change in enzyme concentration.

It is well established that the activity of an enzyme can be drastically affected by post-translational modifications of the enzymatic proteins such as phosphorylations (e.g., Nestler and Greengard, 
1999). Data scattered in the literature suggested that AA could be modulated by the presence of divalent cations such as $\mathrm{Mg}^{2+}$ and $\mathrm{Ca}^{2+}$ that are known to affect also phosphorylation processes (see references in Balthazart et al., 2001) and we therefore hypothesized that the slight discrepancies between effects of $\mathrm{T}$ on AA and on the apparent enzymatic concentration were related to phosphorylations of the enzyme.

In vitro radioenzyme assays first indicated that $\mathrm{AA}$ measured in homogenates of the quail preoptic-hypothalamic region is markedly inhibited within 10-15 min after the exposure of the homogenates to elevated but physiological concentrations of adenosine triphosphate (ATP), $\mathrm{Mg}^{2+}$, and $\mathrm{Ca}^{2+}$. This inhibition was prevented by compounds that chelate divalent ions as well as by kinase inhibitors, strongly suggesting that it is caused by calcium-dependent phosphorylation processes (Balthazart et al., 2001, 2003) (see Figure 2A).

Similar rapid inhibitions were also observed in quail preoptichypothalamic explants maintained in vitro, in which the cellular integrity of the neurons and a large part of their connectivity was preserved. Exposure of these explants to conditions that increase intracellular $\mathrm{Ca}^{2+}$ concentration (e.g., a potassium-induced depolarization) or thapsigargin, a drug that mobilizes intracellular pools of $\mathrm{Ca}^{2+}$ resulted in a very rapid (within $5 \mathrm{~min}$ ) and reproducible inhibition of the enzymatic activity (Balthazart et al., 2001). Similar results were observed following exposure of the explants to glutamatergic agonists (the amino acid AMPA or kainate and, to a lesser extent, $N$-methyl D-aspartate; Balthazart et al., 2006) (see Figure 2B).

Other experiments carried out in vivo have similarly identified rapid changes in AA following visual access or physical (sexual) interactions of a male quail with a female (Figure 2C) as well as following exposure to acute restraint stress (Cornil et al., 2005; Balthazart et al., 2009b; Dickens et al., 2011). These changes are anatomically specific and related precisely to the situation a bird has been exposed to (e.g., AA in POM increases following 5-15 min of restraint stress but decreases after copulation with a female). The mechanisms mediating these changes are currently under investigation and may include rapid phosphorylations of the enzymatic molecule but this remains to be demonstrated. The rapid timecourse of these effects excludes however the possibility that they could be based on changes in the concentration of the enzyme.

At the functional level, it appears very likely that these rapid changes in AA also modulate the local concentration of estrogen in the brain in vivo and recent work from our and other laboratories indicates that these rapid changes in local estrogen concentrations can have a significant functional impact, in particular on the expression of male sexual behavior. In quail specifically, we showed that an acute injection of estradiol facilitates within 5-15 min the expression of both appetitive and consummatory aspects of male sexual behavior (Cornil et al., 2006b). Conversely, a single systemic injection of a large dose of Vorozole, a non-steroidal aromatase inhibitor, quickly (15-30 min) reduces most aspects of sexual behavior in sexually active male quail (Cornil et al., 2006c). Similar rapid effects of estrogens have been identified in rodents (Cross and Roselli, 1999; Kow and Pfaff, 2004; Taziaux et al., 2007) as well as in other birds (e.g., effects on auditory processing in zebra finch: Tremere et al., 2009; Remage-Healey et al., 2010; Maney and
Pinaud, 2011; Tremere and Pinaud, 2011) and fishes (RemageHealey and Bass, 2006). This suggests that such rapid behavioral effects of estrogens are probably quite general and more research is definitely warranted to analyze the causes and consequences of these rapid changes in activity of brain aromatase.

\section{SEX DIFFERENCES IN QUAIL SEXUAL BEHAVIOR}

The expression of male-typical copulatory behaviors is sexually differentiated in quail (Adkins, 1975, 1978; Balthazart et al., 1983): this behavior (mount and copulation with females) is readily observed in males in the standardized laboratory conditions but not in females. It was believed that this behavioral sex difference was caused by the different endocrine environment present in adult birds (high $\mathrm{T}$ concentrations in males but high concentrations of estradiol and progesterone in females) but work in the laboratory of Elizabeth Adkins at Cornell University clearly established that male-typical copulatory behavior is never exhibited by females even after treatment with doses of $\mathrm{T}$ that are behaviorally effective in males (Adkins, 1975, 1978; Balthazart and Schumacher, 1983). Furthermore, plasma T concentrations, although higher in male than in female quail, overlap in the two sexes (Doi et al., 1980; Balthazart et al., 1983, 1987) and should be sufficient to activate male-typical copulatory behavior at least in those females that are at the high end of the natural range of concentrations (Balthazart et al., 1996a). It is thus the way in which male and female brains respond to $\mathrm{T}$ that is sexually differentiated rather than just the $\mathrm{T}$ concentrations.

This differential response to sex steroids develops during ontogeny under the influence of estrogenic ovarian secretions in females during a critical period that ends on day 12 of incubation (Adkins, 1975; Adkins-Regan et al., 1982; Balthazart and AdkinsRegan, 2002). This process can be pharmacologically manipulated in both sexes to obtain in adult birds a male or female behavioral phenotype irrespective of the genetic sex of the subjects. Specifically, injections of estradiol benzoate into male embryos demasculinizes (i.e., completely suppresses) adult copulatory behavior, whereas injections of an aromatase inhibitor in female embryos block demasculinization and lead to adult females that show the full range of male sexual behavior if exposed to exogenous $\mathrm{T}$ (Balthazart and Adkins-Regan, 2002; Balthazart et al., 2009a). During embryonic life, ovarian estrogens thus block the subsequent ability of female quail to perform masculine sexual behavior whereas the male phenotype seems to develop in the absence of hormonal influences. This pattern of sexual differentiation is based on similar principles but is opposite of the mammalian pattern, in which steroids secreted by the male, not the female, play the critical role in the sexual differentiation of reproductive behaviors. Male rats are masculinized and defeminized by $\mathrm{T}$ secreted by the embryonic testes, even if $\mathrm{T}$ exerts most of its effects on brain and behavior after being aromatized into an estrogen (Goy and McEwen, 1980; Cooke et al., 1998).

The reliability of the differential response to $\mathrm{T}$ of adult male or female quail and the ability to fully sex-reverse the behavioral phenotype of adult birds by treating them in ovo with estradiol or with an aromatase inhibitor contributed to the establishment of the Japanese quail as a model for the experimental analysis of sexual differentiation of reproductive behaviors 

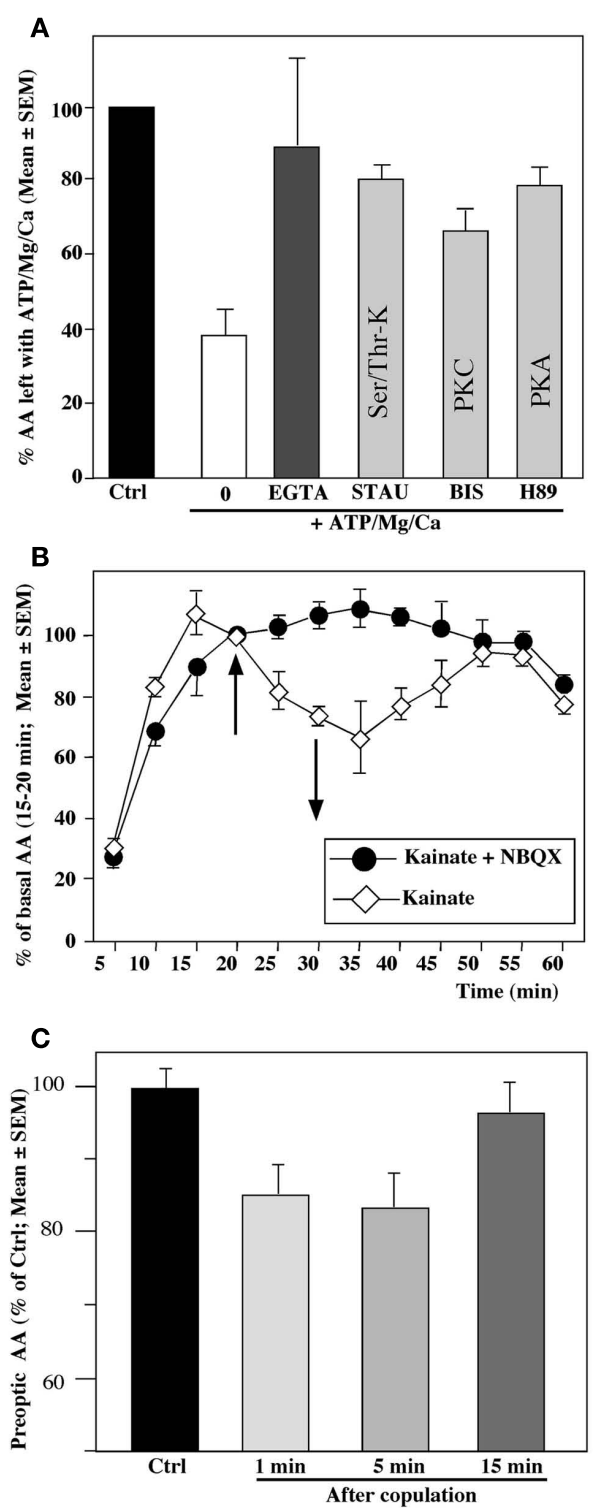

FIGURE 2 | Rapid changes in preoptic aromatase activity (AA) observed in quail brain preoptic area following various in vitro $(A, B)$ or in vivo (C) manipulations. (A) Aromatase activity is drastically decreased from its baseline levels (Ctrl, black column) by a 15-min pre-incubation of hypothalamic homogenates in the presence of ATP, $\mathrm{Mg}^{2+}$, and $\mathrm{Ca}^{2+}(0$; white column). This inhibition is completely blocked by a $\mathrm{Ca}^{2+}$-chelatings agent such as EGTA and by addition of kinase inhibitors such as staurosporine (STAU) which blocks serine/threonine kinases, bisindolylmaleimide (BIS) which blocks protein kinase $\mathrm{C}(\mathrm{PKC})$ or $\mathrm{H} 89$ which blocks protein kinase $A(P K A)$. (B) Aromatase activity in paired hypothalamic explants incubated in vitro in which both explants were exposed for $10 \mathrm{~min}$ (between 20 and $30 \mathrm{~min}$ ) to the glutamate agonist kainate $(100 \mathrm{mM})$; one explant was first pre-incubated with the non-NMDA glutamate antagonist NBOX. The kainate-induced in inhibition of activity is completely abolished by NBOX. (C) Aromatase activity in male quail that were allowed to copulate for 1, 5 or 15 min with a sexually mature female or were handled and returned to their home cage. Brains were collected immediately after the end of the behavior test and AA was quantified in the preoptic area-hypothalamus. Redrawn from data in Balthazart et al. (2003) (A), Balthazart et al. (2006) (B), Cornil et al. (2005) (C).
(Ball and Balthazart, 2011). Numerous studies were performed in an attempt to identify the neuroanatomical or neurochemical features that become sexually differentiated under the influence of embryonic estrogens and control the different behavioral response of adult birds to T. A large number of brain sex differences were identified in this context and have been summarized in several review papers during the last few years (Balthazart et al., 1996a, 2009a; Balthazart and Adkins-Regan, 2002). It must be noted however that most of these differences appear to relate to a differential activation by $\mathrm{T}$ in males and females so that when both sexes are exposed to the same endocrine conditions (e.g., gonadectomized and treated with a same amount of exogenous $\mathrm{T}$ ), these differences disappear (see Balthazart et al., 1996a, 2009a for discussion).

The AA in the preoptic area was identified in the mid-eighties as a potential exception to this rule (Schumacher and Balthazart, 1986) and given the prominent role of preoptic aromatization in the control of male copulatory behavior, we hypothesized that a differential aromatization of $\mathrm{T}$ was potentially responsible for the lack of behavioral response to $\mathrm{T}$ in females. A large number of studies were therefore carried out during the next two decades on the mechanisms that control the preoptic AA in male and female quail and the rest of this review is focused on a summary of the results that were gathered in these studies.

\section{SEX DIFFERENCES IN BRAIN AROMATASE IN GONADALLY INTACT SEXUALLY MATURE BIRDS}

In a first study of AA in the quail brain, we measured this enzymatic activity in both males and females in the hypothalamus-preoptic area (HPOA; the region extending from the tractus septopalliomesencephalicus to the oculomotor nerves) that had been divided in four equivalent blocks along the rostral to caudal axis. A very marked sex difference was detected throughout the rostro-caudal extent of this brain region with males producing two to four times more estrogens than females depending on the brain area considered (Schumacher and Balthazart, 1986; see Figure 3A).

Having around that time also identified a sexually dimorphic nucleus (the volume of the medial preoptic nucleus, POM is significantly larger in males than in females) in the preoptic area of quail (Viglietti-Panzica et al., 1986; Panzica et al., 1987), we wondered whether AA would also be sexually differentiated in this nucleus specifically. The Palkovits micropunch dissection technique (Palkovits and Brownstein, 1983) was therefore adapted to the quail brain and a very sensitive AA assay of these micropunched samples confirmed the presence of a significantly higher AA $( \pm$ double) in the POM of males as compared to females (Figure 3B; Balthazart et al., 1990e). A more recent study confirmed that AA is higher in the POM of males as compared to females although the magnitude of this difference was smaller than what had been reported for the entire preoptic region (female $\mathrm{AA}= \pm 70 \%$ of male AA; Figure 3C) and the sex difference did not reach statistical significance (Cornil et al., 2011). It should be noted, however, that multiple hypothalamic and mesencephalic nuclei were included in that same study and that a statistically significant sex difference in AA (males $>$ females) was detected in the adjacent bed nucleus of the stria terminalis, medial part (BSTM; see Aste et al., $1998 \mathrm{~b}$ for a full description of this brain nucleus in the avian brain based specifically on quail material) as well as in the pooled 


\section{AROMATASE ACTIVITY IN HPOA/POM}
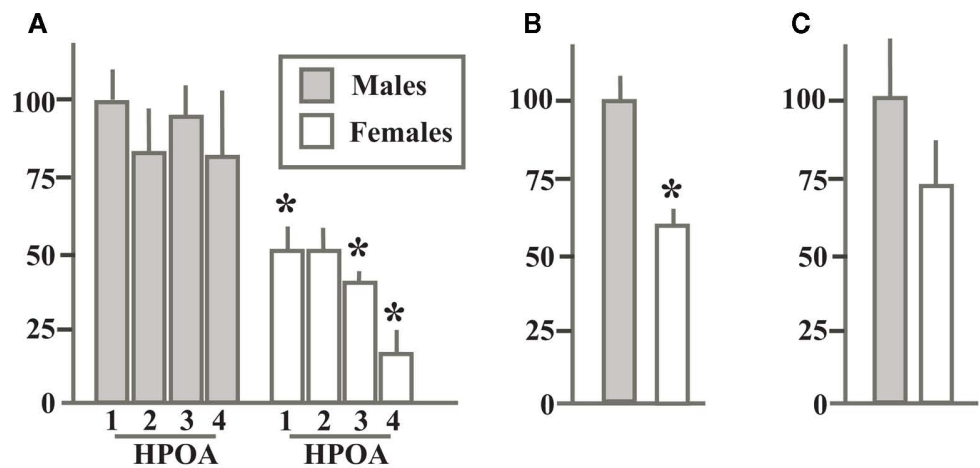

NUMBER OF AROMATASE-IMMUNOREACTIVE CELLS IN POM
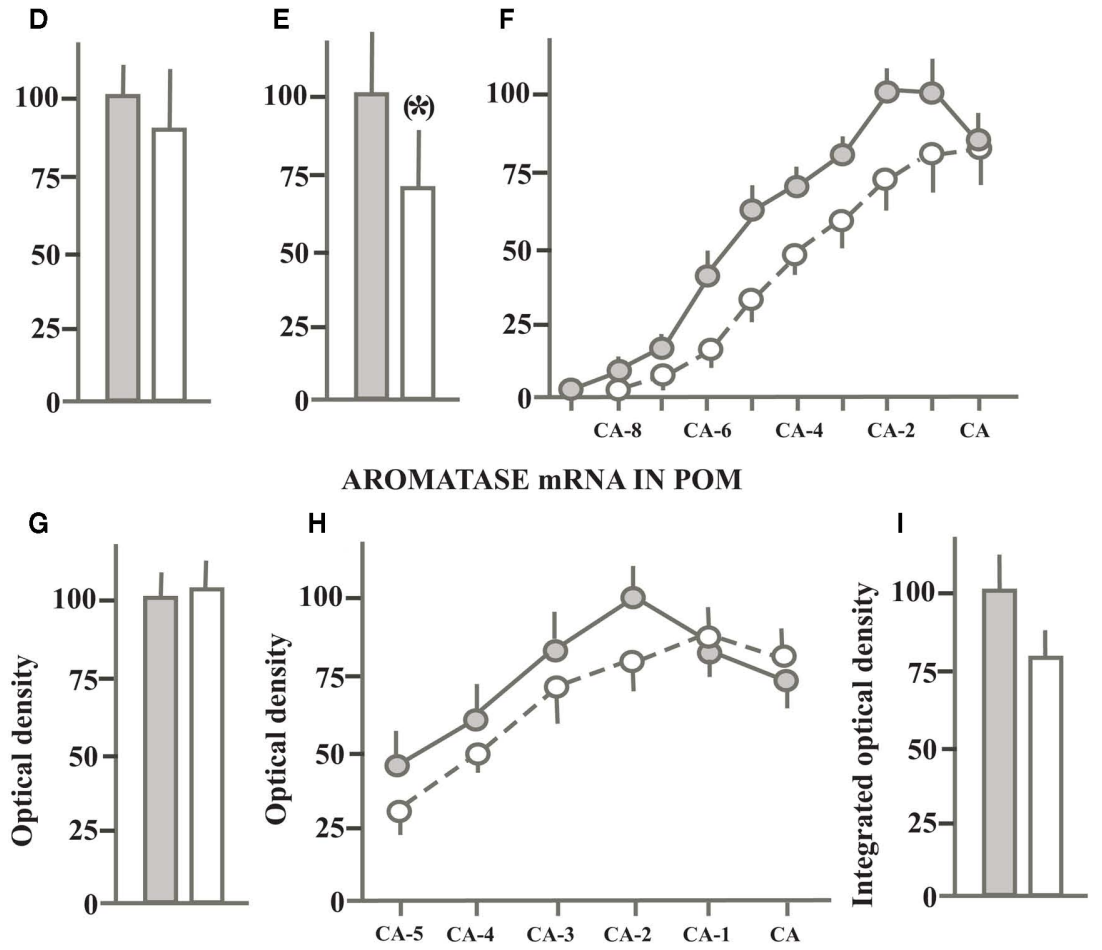

FIGURE 3 | Schematic summary of experiments that compared in sexually mature gonadally intact male and female quail the aromatase activity in the preoptic area (A) or in the medial preoptic nucleus specifically $(B, C)$, the number of aromataseimmunoreactive cells in the POM (D-F) and the density of aromatase mRNA (G-I) quantified by radioactive in situ hybridization. All data are expressed in percentage of the corresponding values in males that are set at $100 \%$ to allow direct comparisons. When serial values were collected along the rostro-caudal axis of the POM, data are expressed as the percentage of the maximal values in males. See text for additional explanations. Redrawn from data in Schumacher and Balthazart (1986) (A), Balthazart et al. (1990e) (B), Cornil et al. (2011) (C), Foidart et al. (1994a) (D), Balthazart et al. (1996b) (E,F), Voigt et al. (2011) (G-I)]. results of POM + BSTM (these groups of aromatase-expressing cells are actually adjacent without any discontinuity). The BSTM was likely included in the dissections of the preoptic area reported in our first study (Schumacher and Balthazart, 1986) and the most recent punch study (Cornil et al., 2011) thus agrees with these original data.

In 1990, an antibody became available that allowed us to identify and localize ARO-ir in the quail brain (Balthazart et al., 1990b,d). Immunocytochemical investigations demonstrated that ARO-ir cells are essentially located in four dense clusters that correspond to (1) the POM, (2) the BSTM, (3) the medio-basal hypothalamus from the level of the dorso-lateral aspects of the VMN of the hypothalamus to the infundibulum, and (4) the nucleus taeniae of the amygdala (see also Foidart et al., 1995).

Soon thereafter, semi-quantitative studies were initiated to investigate whether the sex differences affecting preoptic AA that 
had been previously observed were paralleled by similar differences in the number of ARO-ir cells in POM (and BSTM). A first study, providing an estimate of the total number of ARO-ir cells in the POM failed to detect any substantial sex difference (Male: $3045 \pm 250$ cells vs. Females: $2747 \pm 524$ cells, Figure 3D) although the analysis of the distribution of ARO-ir cells along the rostrocaudal axis of the POM indicated that males had more ARO-ir cells than females in the caudal part of the nucleus whereas the opposite was true in its rostral part (Foidart et al., 1994a).

A second experiment implemented a three-dimensional analysis of these cells to investigate whether the difference in preoptic AA that had been described was possibly due to a discrete sex difference in the number of ARO-ir cells that would not be detected in global counts that considered the entire nucleus (Balthazart et al., 1996b). The total numbers of POM ARO-ir cells in this study was shown to be significantly larger $(30 \%)$ in males than in females ( $10584 \pm 2080$ vs. $7238 \pm 1925$, no attention should be paid to absolute numbers, differences between experiments only relate to the sampling procedure; see Figure 3E for results expressed as percentage of male data). The largest difference between males and females was again localized in the caudal part of the POM (Balthazart et al., 1996b; Figure 3F) but in no case did we find a sex difference in the number of ARO-ir cells of a magnitude as large as the difference affecting AA in the preoptic area or in the POM specifically (two to threefold difference).

The partial (Harada et al., 1992) and then nearly complete (Balthazart et al., 2003) cloning and sequencing of quail aromatase also allowed us more recently to prepare in situ hybridization probes facilitating the visualization and quantification of the aromatase mRNA. The distribution of aromatase mRNA matched very closely with the results of the previous immunocytochemical studies with the densest signal being observed in the POM, BSTM, and in the medio-basal hypothalamus. Additional weaker signal was detected in the rostral forebrain, arcopallium, and mesencephalic regions (Aste et al., 1998a; Voigt et al., 2007). Quite surprisingly, the comparative analysis of the hybridization signal in males and females revealed, however, a complete absence of sex difference in the optical density of the signal in the POM (Figure 3G) and medio-basal hypothalamus. A reversed sex difference (female density higher than male density) was even detected in the BSTM (Voigt et al., 2007), where we had in contrast detected a higher level of AA in males than in females (Cornil et al., 2011). Based on the immunocytochemical results presented previously, we suspected that a differential density of hybridization signal could be present in discrete areas of the POM. Therefore we also measured this parameter in a systematic fashion along the rostro-caudal axis of the nucleus but no reliable sex difference could be detected in this manner (Figure 3H; Voigt et al., 2007).

The area covered by the dense cluster of ARO-ir cells had been shown to match precisely the boundaries of the POM as defined in Nissl staining. As previously mentioned, the POM volume is sexually differentiated (males > females; Viglietti-Panzica et al., 1986; Panzica et al., 1987) and accordingly the volume defined by the cluster of ARO-ir cells is larger in males than in females (Balthazart et al., 1996b). This sex difference was also confirmed by in situ hybridization studies, which identified a significantly larger volume defined by a dense hybridization signal in males than in females (Voigt et al., 2007). In an attempt to obtain an estimate of the total amount of aromatase mRNA present in the male and female POM, we also calculated the integrated optical density of the corresponding hybridization signal defined as the product of the signal optical density by the volume occupied (see Roselli et al., 2004). This integrated optical density was larger in males than in females (Figure 3I; effect driven by the volume difference) but the difference had a small magnitude and was associated with a substantial amount of inter-individual variance so that it was not statistically significant (Voigt et al., 2007).

Taken together these results demonstrate the presence of a reliable (approximately twofold) sex difference in preoptic AA localized specifically in the sexually dimorphic POM and in the adjacent BSTM. However this enzymatic sex difference does not correspond to a large difference in the number of ARO-ir cells in POM (30\% difference in one study, no difference in another) and a very small or no sex difference could be detected in the density of aromatase mRNA. Also, very few sex differences have been detected to date based on the analysis of the distribution of androgen or estrogen receptors in the quail brain (Watson and Adkins-Regan, 1989; Voigt et al., 2009). These discrepancies between measures of $\mathrm{AA}$ and its expression raise obvious questions concerning the mechanisms generating the sex difference in enzymatic activity. We shall return to this question after a description of sex differences in AA and expression in adults birds exposed to similar endocrine conditions.

\section{SEX DIFFERENCES IN BRAIN AROMATASE IN GONADECTOMIZED BIRDS TREATED WITH SEX STEROIDS}

Studies of brain AA had been initiated to explain the action of T on male sexual behavior, but also to test whether sex differences in AA could be responsible for the difference in behavioral response to $\mathrm{T}$ between males and females. If this were the case, one should then expect to find a more active AA in males than in females not only in sexually mature birds but also in gonadectomized subjects treated with a same dose of $\mathrm{T}$ (since this is the endocrine condition in which males show an active copulatory behavior but females do not; Adkins, 1975; Balthazart et al., 1983; Balthazart and Adkins-Regan, 2002). The studies of AA, of ARO-ir neurons and of aromatase mRNA described in the previous section were therefore carried out also in castrated males and ovariectomized females that had been treated with identical Silastic ${ }^{\mathrm{TM}}$ implants filled with crystalline $T$ that established plasma concentrations of the steroid similar to those normally observed in sexually mature males. Results of these studies are summarized in Figure 4.

An initial study of gonadectomized birds treated with $40 \mathrm{~mm}$ long implants filled with $\mathrm{T}(\mathrm{GNX}+\mathrm{T})$ in which AA was assayed in the entire HPOA dissected in 4 equivalent blocks along the rostro-caudal axis had indicated the presence of a very substantial sex difference (two to threefold) affecting AA throughout this area (see Figure 4A; Schumacher and Balthazart, 1986). A second experiment published in the same paper suggested, however, that the magnitude of this sex difference in GNX $+\mathrm{T}$ birds was much smaller than originally thought. The Vmax of the enzyme measured during incubations of entire HPOA with increasing doses of substrate was calculated to be $1 \mathrm{pmol} / \mathrm{mg}$ protein $/ \mathrm{h}$ in males and $0.75 \mathrm{pmol} / \mathrm{mg}$ protein $/ \mathrm{h}$ in females. 


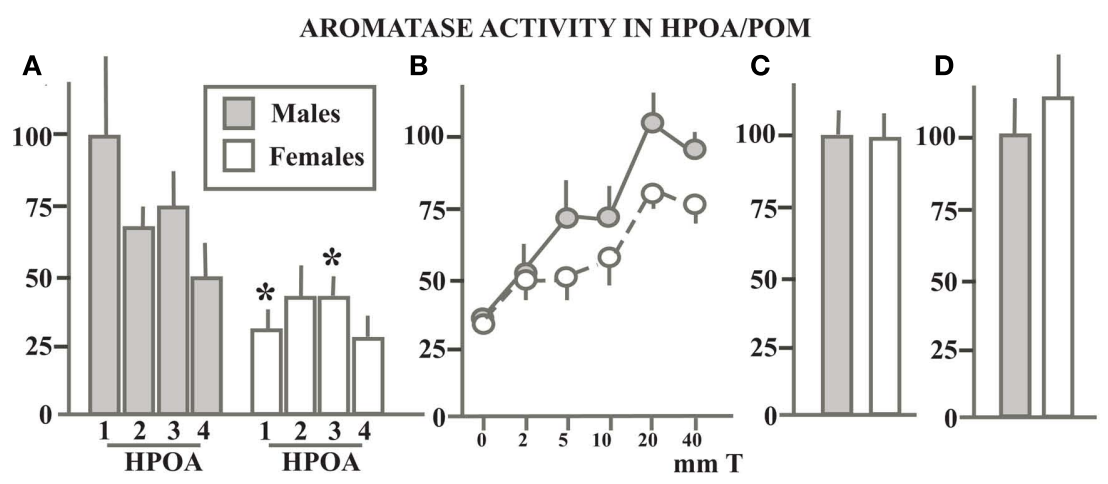

NUMBER OF AROMATASE-IMMUNOREACTIVE CELLS IN POM
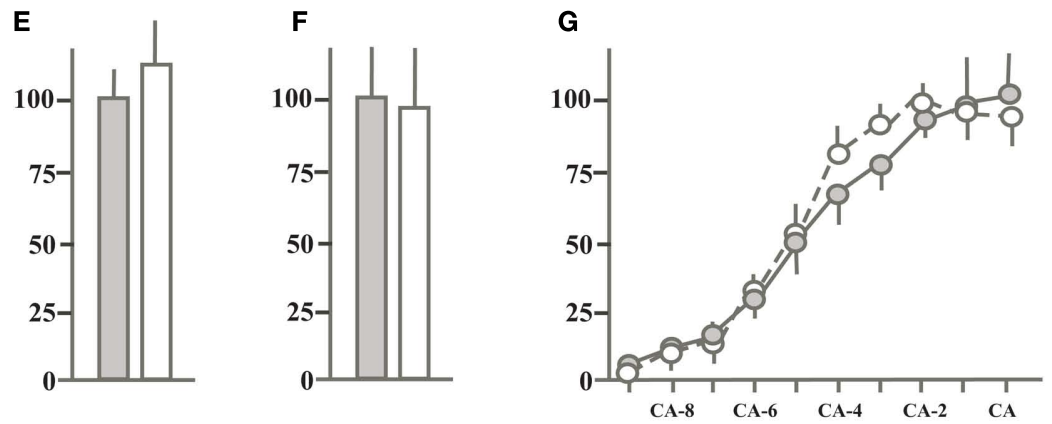

AROMATASE mRNA IN POM
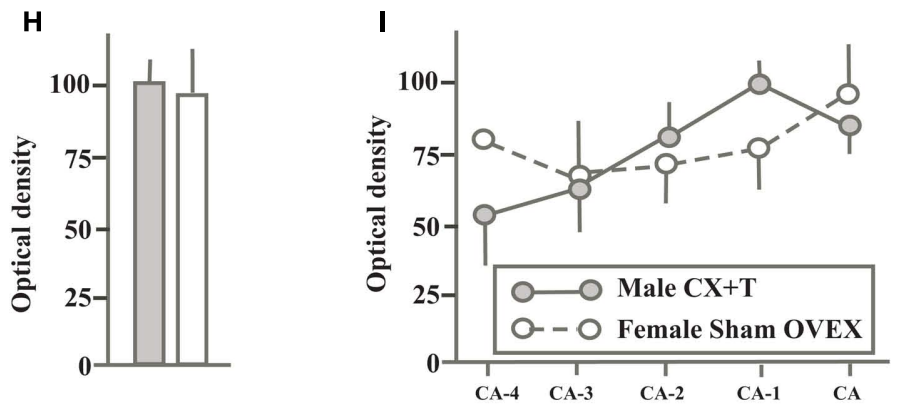

FIGURE 4 | Schematic summary of experiments that compared in gonadectomized sexually mature male and female quail that were treated with the same dose of exogenous testosterone the aromatase activity in the preoptic area $(A)$ or in the medial preoptic nucleus specifically $(B, C)$, the number of aromatase-immunoreactive cells in the POM detected by immunocytochemistry (D-F) and the density of aromatase mRNA (G-I) quantified by radioactive in situ hybridization. All data are expressed as a percentage of the corresponding values in males that are set at $100 \%$ to allow direct comparisons. When serial values were collected along the rostro-caudal axis of the POM, data are expressed as the percentage of the maximal values in males. See text for additional comparisons. Redrawn from data in Schumacher and Balthazart (1986) (A), Balthazart et al. (1990c) (B), Balthazart et al. (1990e) (C), Cornil et al. (2011) (D), Foidart et al. (1994a) (E), Balthazart et al. (1996b) (F,G), Voigt et al. (2011) (H,I).
In a subsequent study, we investigated whether different doses of $\mathrm{T}$ would reveal more robust sex differences in the $\mathrm{T}$ induction of AA in males and females. For this purpose, groups of gonadectomized birds of both sexes were treated with T-filled Silastic ${ }^{\mathrm{TM}}$ implants of various lengths ranging between 2 and $40 \mathrm{~mm}$ or with empty implants as control (Balthazart et al., 1990c). As shown in Figure 4B, the increasing doses of $\mathrm{T}$ increased $\mathrm{AA}$ in the entire HPOA in a dose-dependent manner. This induction was numerically and statistically larger in males than in females. However the magnitude of this sex difference was roughly similar through the range of doses that were tested and never exceed $25-30 \%$.

In two independent studies, AA was also quantified in the POM of GNX + T males and females that was dissected by the Palkovits punch technique. These two studies were performed more than 20 years apart, the first one before the precise localization of AROir neurons had been described (Balthazart et al., 1990e), the second one much later so that the microdissection could be guided by this anatomical information (Cornil et al., 2011). Interestingly, both studies failed to identify a sex difference in AA within this nucleus 
(Figures 4C,D). Together, these studies suggest that the small sex difference in AA detected in the HPOA of GNX $+\mathrm{T}$ birds might not be located in POM as dissected in micropunches studies and that the sex difference in AA detected in the POM of sexually mature birds is no longer present when birds are exposed to the same endocrine conditions. This conclusion was largely confirmed by studies analyzing the preoptic aromatase by immunocytochemical detection of the enzymatic protein or by in situ hybridization of the corresponding mRNA.

Two independent experiments quantified in great detail the numbers of ARO-ir cells present in the POM of GNX + T males and females. The first of these studies failed to find any sex difference in the total number of ARO-ir cells in the POM as well as in the number of these cells at different rostro-caudal levels within this nucleus (Foidart et al., 1994a). In the second study, these cells were quantified in even greater detail by considering their three-dimensional distribution (Balthazart et al., 1996b). No sex difference was again detected in the total number of ARO-ir cells in the entire POM (Figure 4F), in the number of cells at different rostro-caudal levels (Figure 4G), and in more discrete locations in the three dimensions (data not shown, see Balthazart et al., 1996b).

Similar conclusions were reached by quantitative in situ hybridization in a recent study that analyzed the density and distribution (volume of dense expression) of the aromatase mRNA in gonadectomized male and female quail as well as in gonadectomized males treated with exogenous $\mathrm{T}$ and in females that had regrown a fully functional ovary after an unsuccessful ovariectomy so that they were in adulthood laying eggs and exposed to a full complement of gonadal steroids (estradiol, progesterone,...) typical of their sex (Voigt et al., 2011). In both sexes, gonadectomy markedly decreased the density of aromatase mRNA in the POM, BSTM, and medio-basal hypothalamus. Exposure to gonadal steroids typical of their sex enhanced aromatase expression in these three nuclei but in no location could a difference favoring males be identified based on the density of the mRNA. In particular, the average density of aromatase mRNA in the entire POM was similar in males and females (Figure $\mathbf{4 H}$ ) and the same was true at different rostro-caudal levels throughout the nucleus (Figure 4I). A reverse sex difference (females $>$ males) was even identified in the BSTM of these birds as previously seen in gonadally intact sexually mature birds (Voigt et al., 2007; see previous section).

Taken together these data lead to the important conclusion that the sexually differentiated behavioral response to $\mathrm{T}$ in quail is not simply the result of a differential effect of T on AA and even less on aromatase transcription. Indeed multiple experiments demonstrate that $\mathrm{T}$ always activates in a very reliable manner copulatory behavior in males but never has this effect in females. In contrast, the sex difference in AA is usually present although with a variable magnitude in gonadally intact birds but it is very variable in birds treated with exogenous $\mathrm{T}$, ranging from being present and significant like in intact birds to completely missing (males $=$ females) whereas behavior is still highly different. The reliable behavioral difference thus cannot be based only on an unreliable enzymatic difference even if the latter eventually contributes to some extent to the former. This conclusion is actually consistent with the results of behavioral experiments showing that treatment of gonadectomized birds with exogenous estradiol, which should by-pass the putative bottleneck created by a more limited aromatization in females, activates sexual behavior in males but still not in females (Schumacher and Balthazart, 1983).

\section{SEX DIFFERENCES AFFECTING NON-GENOMIC CONTROLS OF BRAIN AROMATASE}

These data also raise an important question concerning the mechanisms that control the sex difference in AA reliably observed in sexually mature birds since this enzymatic difference is not associated with a sex difference in aromatase mRNA concentration nor a significant sex difference in the number of preoptic ARO-ir neurons. We demonstrated that in males AA is regulated by $\mathrm{T}$ via changes in the transcription of corresponding mRNA but also in the short-term by non-genomic mechanisms based at least in part on phosphorylation processes (Balthazart et al., 2004; Balthazart and Ball, 2006). These post-translational changes potentially create a discordance between the amount of enzyme and the actual enzymatic activity present at a given location and at a given time. We therefore wondered whether a differential degree of aromatase phosphorylation in males and females could explain the presence of sex differences in AA in the absence of sex differences in aromatase mRNA concentration. These studies were conducted in gonadally intact sexually mature birds since it is in these conditions that the most reliable sex difference in AA are detected (see Konkle and Balthazart, 2011).

A first set of experiments involving the incubation of male or female HPOA homogenates with increasing concentrations of substrate (tritiated androstenedione) for various durations confirmed the presence of a significantly higher (about double) enzymatic activity in males as compared to females. Based on the saturation analysis, the apparent affinity $(\mathrm{Km})$ of the enzyme for its substrate was however similar in males and females.

We then tested whether phosphorylating conditions that had been shown to affect in a rapid manner AA in males had a similar effect in females. Homogenates of HPOA blocks from adult male and female quail were prepared in a buffer that did or did not contain EGTA (ethylene glycol tetraacetic acid, a compound chelating divalent ions) and then pre-incubated for $10 \mathrm{~min}$ in the presence or absence of ATP, $\mathrm{Mg}^{2+}$, and $\mathrm{Ca}^{2+}$ (ATP-Mg-Ca). AA was then assayed in these samples. This experiment confirmed (1) the significantly higher activity in males as compared to females, (2) that exposure to a divalent ion chelating agent (EGTA) increases $\mathrm{AA}$, and (3) that pre-incubation with ATP-Mg-CA significantly decreases the enzyme activity. Quite interestingly these effects were not identical in males and females. A three way Analysis of Variance detected, besides the significant main effects (Sex, EGTA, ATP-Mg-Ca), significant interactions between the sex of the birds and the effects of EGTA on the one hand, and of ATP-Mg-Ca on the other hand (Konkle and Balthazart, 2011). Specifically, effects of EGTA were more pronounced in males than in females while effects of ATP-Mg-Ca also had larger amplitude in males as compared to females (Figure 5).

Additional analysis taking into account the different basal aromatase in the two sexes (males $>$ females) suggested that the interaction between Sex and ATP-Mg-Ca only reflects this 


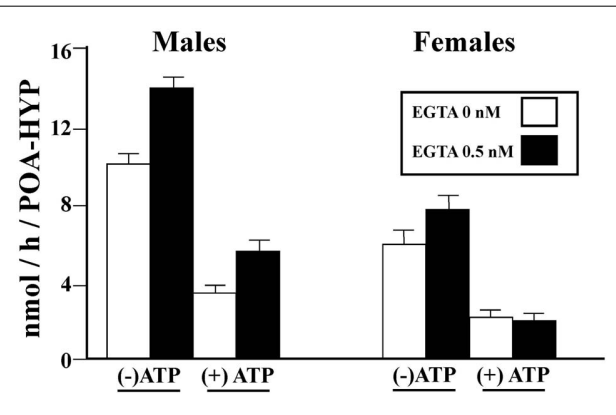

FIGURE 5 | Calcium-dependent changes in aromatase activity in the male and female quail HPOA. Males and female tissue homogenates were exposed to 0 or $0.5 \mathrm{mM}$ EGTA combined with the presence or absence of ATP $/ \mathrm{Mg}^{2+} / \mathrm{Ca}^{2+}(\mathrm{ATP})$, thus creating four different experimental conditions in each sex. Redrawn form data in Konkle and Balthazart (2011).

differential baseline quite normally associated with a larger magnitude of experimental changes. In contrast, however, the interaction between Sex and EGTA action was still significant when this different basal activity was taken into account thus clearly indicating that chelating divalent ions markedly increase AA in males but not or less so in females.

One interpretation of these data is that, in control conditions, brain AA is suppressed more by $\mathrm{Ca}^{2+}$ and $\mathrm{Mg}^{2+}$ in males than in females so that the release from this inhibition has more prominent effects in males. This points to a potentially interesting sex difference in the regulation of aromatase by the intracellular ionic environment but, returning to the original question that prompted performance of these experiments, it is clear that this differential regulation does not explain the higher basal activity of males in the absence of a differential concentration of aromatase mRNA. If enzymatic activity is lower in females while they seem to have a similar amount of aromatase mRNA, one would rather expect that the enzyme is chronically inhibited more in females than in males. Additional work will therefore be required to explain this intriguing discrepancy.

Another experiment also demonstrated that a variety of kinase inhibitors including genistein (a general tyrosine kinase inhibitor), staurosporine (a general serine/threonine kinase inhibitor), and bisindolylmaleimide (a protein kinase C inhibitor) all significantly block the inhibitory effects of a pre-incubation with ATP-Mg-Ca on AA in both males and females. There was again a significant interaction between the sex of the birds and the effects of these inhibitors but it presumably resulted only from the higher basal activity in males because the interaction was no longer significant when male and female data were expressed as percentage of the control values in their respective sex (see Konkle and Balthazart, 2011 for more detail).

\section{CONCLUSION AND PERSPECTIVES}

Since the discovery of an active AA in the brain by Naftolin et al. (1972, 1975), a tremendous amount of data have been accumulated concerning the functional significance of this enzyme and the mechanisms controlling its activity. The Japanese quail and birds in general have always been at the forefront of this progress because these species display a much higher enzymatic activity than typical laboratory mammals such as rats and mice and the analysis of the activity of the enzyme and of its neuroanatomical distribution is greatly facilitated.

In quail, it has been clearly established that the aromatization of $\mathrm{T}$ into estradiol in the preoptic area is a critical limiting step in the activation of male copulatory behavior. One of the first neurochemical effects of $\mathrm{T}$ in the preoptic area is actually to increase local AA. With the availability of antibodies against aromatase and the sequencing of its mRNA allowing preparation of probes for in situ hybridization, it became possible to analyze the control of aromatase at all these levels. These studies revealed that the activation of AA by $\mathrm{T}$ is largely, if not exclusively, explained by an increased concentration of the corresponding mRNA presumably resulting from a stimulation of the transcription of the corresponding gene.

Because T never activates male-typical copulatory behavior in female quail and because initial studies indicated that the preoptic $\mathrm{AA}$ is higher in males than in females, it was suspected that this differential production of estrogens in the brain could be a critical factor responsible for the lack of behavioral activation in females. Subsequent studies revealed, however, that this sex difference in AA is not reliable when males and females are gonadectomized and treated with $\mathrm{T}$, and that treating females with estrogens still does not activate male-typical copulatory behavior. This simplistic explanation of the behavioral difference is thus simply not true and more work on this topic is therefore required.

This work comparing AA, ARO-ir cells, and aromatase mRNA in males and females interestingly revealed that sex differences observed when measuring enzymatic activity are not necessarily present at the level of the mRNA concentrations. It was hypothesized that these discrepancies could reflect post-translational controls of the enzymatic activity that were known to take place in males following phosphorylation processes presumably affecting the aromatase protein itself. Experiments carried out so far indicate that rapid inhibitions of AA by phosphorylations occur in females as they do in males but so far the pattern of these effects does not seem to be able to explain the sex difference in preoptic AA. Additional work on the actual intracellular concentrations of $\mathrm{Ca}^{2+}$ in the male and female brains should however be carried out to determine what are the physiological conditions under which aromatase operates in vivo.

Additionally, the functional significance of brain AA, especially in females, and the role(s) of rapid changes in brain estrogens production are still the subject of active research. In an alternative avian model, the telencephalic auditory system of the zebra finch, it has now been shown that the aromatase protein and AA are located in part at the level of pre-synaptic boutons (Peterson et al., 2005; Rohmann et al., 2007), that rapid changes in local estrogen concentrations (as measured by in vivo dialysis coupled to very sensitive radioimmunoassay) take place in response to social experiences (e.g., hearing songs: Remage-Healey et al., 2008) and that these rapid changes in estrogen concentration have rapid, specific, and enduring effects (several hours) on the processing and discrimination of auditory signals (Tremere et al., 2009; Remage-Healey et al., 2010; Maney and Pinaud, 2011). In quail, we also collected evidence indicating that rapid changes in estrogen availability that should result from rapid changes in local AA significantly modulate the expression of appetitive and consummatory aspects of 
male sexual behavior (Cornil et al., 2006b,c) and similar results have been observed in rats (Cross and Roselli, 1999) and mice (Taziaux et al., 2007). Taken together these results demonstrate that (1) estrogens are produced at the pre-synaptic level, (2) their production changes rapidly within minutes if not seconds, (3) their production is altered by changes in the environment and in neurotransmitter activity, and (4) their action presumably at the neuron membrane rapidly affects behavioral activity, thus strongly supporting the idea that estrogens produced by aromatization in the brain behave like neuromodulators if not neurotransmitters (Balthazart and Ball, 2006; Saldanha et al., 2011). Numerous

\section{REFERENCES}

Absil, P., Baillien, M., Ball, G. F., Panzica, G., and Balthazart, J. (2001). The control of preoptic aromatase activity by afferent inputs in Japanese quail. Brain Res. Rev. 37, 38-58.

Adkins, E. K. (1975). Hormonal basis of sexual differentiation in the Japanese quail. J. Comp. Physiol. Psychol. $89,61-71$.

Adkins, E. K. (1977). Effects of diverse androgens on the sexual behavior and morphology of castrated male quail. Horm. Behav. 8, 201-207.

Adkins, E. K. (1978). Sex steroids and the differentiation of avian reproductive behavior. Am. Zool. 18, 501-509.

Adkins, E. K., Boop, J. J., Koutnik, D. L., Morris, J. B., and Pniewski, E. E. (1980). Further evidence that androgen aromatization is essential for the activation of copulation in male quail. Physiol. Behav. 24, 441-446.

Adkins, E. K., and Nock, B. L. (1976). The effects of the antiestrogen CI628 on sexual behavior activated by androgen and estrogen in quail. Horm. Behav. 7, 417-429.

Adkins, E. K., and Pniewski, E. E. (1978). Control of reproductive behavior by sex steroids in male quail. J. Comp. Physiol. Psychol. 92, 1169-1178.

Adkins-Regan, E. K., Pickett, P., and Koutnik, D. (1982). Sexual differentiation in quail: conversion of androgen to estrogen mediates testosterone-induced demasculinization of copulation but not other male characteristics. Horm. Behav. 16, 259-278.

Alexandre, C., and Balthazart, J. (1986). Effects of metabolism inhibitors, antiestrogens and antiandrogens on the androgen and estrogen induced sexual behavior in Japanese quail. Physiol. Behav. 38, 581-591.

Aste, N., Panzica, G. C., VigliettiPanzica, C., Harada, N., and Balthazart, J. (1998a). Distribution and effects of testosterone on aromatase mRNA in the quail forebrain: a non-radioactive in situ hybridization study. J. Chem. Neuroanat. 14, 103-115.

Aste, N., Balthazart, J., Absil, P., Grossmann, R., Mülhbauer, E., VigliettiPanzica, C., and Panzica, G. C. (1998b). Anatomical and neurochemical definition of the nucleus of the stria terminalis in Japanese quail (Coturnix japonica). J. Comp. Neurol. 396, 141-157.

Ball, G. F., and Balthazart, J. (2002). "Neuroendocrine mechanisms regulating reproductive cycles and reproductive behavior in birds," in Hormones, Brain and Behavior, eds D.W. Pfaff, A. P. Arnold, A. M. Etgen, S. E. Fahrbach, and R. T. Rubin (San Diego, CA: Academic Press), 649-798.

Ball, G. F., and Balthazart, J. (2008). Individual variation and the endocrine regulation of behaviour and physiology in birds: a cellular/molecular perspective. Philos. Trans. R. Soc. Lond. B Biol. Sci. 363, 1699-1710.

Ball, G. F., and Balthazart, J. (2011). Japanese quail as a model system for studying the neuroendocrine control of reproductive and social behaviors. ILAR J. 51, 310-325.

Balthazart, J. (1989). "Steroid metabolism and the activation of social behavior," in Advances in Comparative and Environmental Physiology, 1st Edn, Vol. 3, ed. J. Balthazart (Berlin: Springer Verlag), 105-159.

Balthazart, J., and Adkins-Regan, E. (2002). "Sexual differentiation of brain and behavior in birds," in Hormones, Brain and Behavior, eds D. W. Pfaff, A. P. Arnold, A. M. Etgen, S. E. Fahrbach, and R. T. Rubin (San Diego, CA: Academic Press), 223-301.

Balthazart, J., Arnold, A. P., and AdkinsRegan, E. (2009a). "Sexual differentiation of brain and behavior in birds," in Hormones, Brain and Behavior, eds D. W. Pfaff, A. P. Arnold, A. M. Etgen, S. E. Fahrbach, and R. T. Rubin (San Diego, CA: Academic Press), 1745-1787.

questions remain, however, concerning the specific function of brain estrogens in the control of behavior, sensory physiology, and sex difference affecting these two processes.

\section{ACKNOWLEDGMENTS}

The research from our laboratory described in this paper was supported by a grant of the NIMH (R01 MH50388) to Gregory F. Ball and Jacques Balthazart and by grants from the Belgian FRFC (Nbr. 2.4537.9), the University of Liège (Crédits spéciaux) to Jacques Balthazart. Thierry D. Charlier is Research Associate at the University of Liège, Charlotte A. Cornil is F.R.S-FNRS Research Associate.

Balthazart, J., Cornil, C. A., Charlier, T. D., Taziaux, M., and Ball, G. F. (2009b). Estradiol, a key endocrine signal in the sexual differentiation and activation of reproductive behavior in quail. J. Exp. Zool. A Ecol. Genet. Physiol. 311, 323-345.

Balthazart, J., Baillien, M., and Ball, G. F. (2001). Rapid and reversible inhibition of brain aromatase activity. $J$. Neuroendocrinol. 13, 63-73.

Balthazart, J., Baillien, M., and Ball, G. F. (2006). Rapid control of brain aromatase activity by glutamatergic inputs. Endocrinology 147, 359-366.

Balthazart, J., Baillien, M., Charlier, T. D., and Ball, G. F. (2003). Calcium-dependent phosphorylation processes control brain aromatase in quail. Eur. J. Neurosci. 17, 1591-1606.

Balthazart, J., Baillien, M., Cornil, C. A., and Ball, G. F. (2004). Preoptic aromatase modulates male sexual behavior: slow and fast mechanisms of action. Physiol. Behav. 83, 247-270.

Balthazart, J., and Ball, G. F. (2006). Is brain estradiol a hormone or a neurotransmitter? Trends Neurosci. 29, 241-249.

Balthazart, J., and Ball, G. F. (2007). Topography in the preoptic region: differential regulation of appetitive and consummatory male sexual behaviors. Front. Neuroendocrinol. 28:161-178.

Balthazart, J., Delville, Y., Sulon, Y., and Hendrick, J. C. (1987). Plasma levels of luteinizing hormone and of five steroids in photostimulated, castrated and testosterone-treated male and female Japanese quail (Coturnix coturnix japonica). Gen. Endocrinol. (Life Sci. Adv.) 5, 31-36.

Balthazart, J., Evrard, L., and Surlemont, C. (1990a). Effects of the nonsteroidal aromatase inhibitor, R76713 on testosterone-induced sexual behavior in the Japanese quail (Coturnix coturnix japonica). Horm. Behav. 24, 510-531.

Balthazart, J., Foidart, A., and Harada, N. (1990b). Immunocytochemical localization of aromatase in the brain. Brain Res. 514, 327-333.

Balthazart, J., Foidart, A., and Hendrick, J. C. (1990c). The induction by testosterone of aromatase activity in the preoptic area and activation of copulatory behavior. Physiol. Behav. 47, 83-94.

Balthazart, J., Foidart, A., Surlemont, C., Vockel, A., and Harada, N. (1990d). Distribution of aromatase in the brain of the Japanese quail, ring dove, and zebra finch: an immunocytochemical study. J. Comp. Neurol. 301, 276-288.

Balthazart, J., Schumacher, M., and Evrard, L. (1990e). Sex differences and steroid control of testosteronemetabolizing enzyme activity in the quail brain. J. Neuroendocrinol. 2, 675-683.

Balthazart, J., and Foidart, A. (1993). Brain aromatase and the control of male sexual behavior. J. Steroid Biochem. Mol. Biol. 44, 521-540.

Balthazart, J., and Schumacher, M. (1983). "Testosterone metabolism and sexual differentiation in quail," in Hormones and behaviour in higher vertebrates, eds J. Balthazart, E. Pröve, and R. Gilles (Berlin: Springer-Verlag), 237-260.

Balthazart, J., Schumacher, M., and Malacarne, G. (1985). Interaction of androgens and estrogens in the control of sexual behavior in male Japanese quail. Physiol. Behav. 35, 157-166.

Balthazart, J., Schumacher, M., and Ottinger, M. A. (1983). Sexual differences in the Japanese quail: behavior, morphology and intracellular metabolism of testosterone. Gen. Comp. Endocrinol. 51, 191-207.

Balthazart, J., Stoop, R., Foidart, A., and Harada, N. (1994). Synergistic control by androgens and estrogens of aromatase in the quail brain. Neuroreport 5, 1729-1732.

Balthazart, J., and Surlemont, C. (1990). Androgen and estrogen action in the preoptic area and activation of copulatory behavior in quail. Physiol. Behav. 48, 599-609. 
Balthazart, J., Tlemçani, O., and Ball, G. F. (1996a). Do sex differences in the brain explain sex differences in the hormonal induction of reproductive behavior? What 25 years of research on the Japanese quail tells us. Horm. Behav. 30, 627-661.

Balthazart, J., Tlemçani, O., and Harada, N. (1996b). Localization of testosterone-sensitive and sexually dimorphic aromataseimmunoreactive cells in the quail preoptic area. J. Chem. Neuroanat. $11,147-171$

Beach, F. A. (1948). Hormones and Behavior. New York: Paul B. Hoeber, Inc., 1-368.

Breuner, C. W., Lynn, S. E., Julian, G. E., Cornelius, J. M., Heidinger, B. J., Love, O. P., Sprague, R. S., Wada, H., and Whitman, B. A. (2006). Plasma-binding globulins and acute stress response. Horm. Metab. Res. 38, 260-268.

Callard, G. V., Petro, Z., and Ryan, K. J. (1978a). Conversion of androgen to estrogen and other steroids in the vertebrate brain. Am. Zool. 18, 511-523.

Callard, G. V., Petro, Z., and Ryan, K. J. (1978b). Phylogenetic distribution of aromatase and other androgenconverting enzymes in the central nervous system. Endocrinology 103, 2283-2290.

Charlier, T. D. (2009). Importance of steroid receptor coactivators in the modulation of steroid action on brain and behavior. Psychoneuroendocrinology 34(Suppl. 1), S20-S29.

Cooke, B., Hegstrom, C. D., Villeneuve, L. S., and Breedlove, S. M. (1998). Sexual differentiation of the vertebrate brain: principles and mechanisms. Front. Neuroendocrinol. 19, 323-362.

Cornil, C. A. (2009). Rapid regulation of brain oestrogen synthesis: the behavioural roles of oestrogens and their fates. J. Neuroendocrinol. 21, 217-226.

Cornil, C. A., Ball, G. F., and Balthazart, J. (2006a). Functional significance of the rapid regulation of brain estrogen action: where do the estrogens come from? Brain Res. 1126, 2-26.

Cornil, C. A., Dalla, C., PapadopoulouDaifoti, Z., Baillien, M., and Balthazart, J. (2006b). Estradiol rapidly activates male sexual behavior and affects brain monoamine levels in the quail brain. Behav. Brain Res. 166, 110-123.

Cornil, C. A., Taziaux, M., Baillien, M., Ball, G. F., and Balthazart, J. (2006c). Rapid effects of aromatase inhibition on male reproductive behaviors in Japanese quail. Horm. Behav. 49, 45-67.
Cornil, C. A., Ball, G. F., Balthazart, J., and Charlier, T. D. (2011). Organizing effects of sex steroids on brain aromatase activity in quail. PLoS ONE 6, e19196. doi: 10.1371/journal.pone.0019196

Cornil, C. A., Dalla, C., PapadopouluDaifoti, Z., Baillien, M., Dejace, C., Ball, G. F., and Balthazart, J. (2005). Rapid decreases in preoptic aromatase activity and brain monoamine concentrations after engaging in male sexual behavior. Endocrinology 146, 3809-3820.

Cross, E., and Roselli, C. E. (1999). 17beta-estradiol rapidly facilitates chemoinvestigation and mounting in castrated male rats. Am. J. Physiol. Regul. Integr. Comp. Physiol. 276, R1346-R1350.

Deviche, P., Breuner, C., and Orchinik, M. (2001). Testosterone, corticosterone, and photoperiod interact to regulate plasma levels of binding globulin and free steroid hormone in dark-eyed Juncos, Junco hyemalis. Gen. Comp. Endocrinol. 122, 67-77.

Dickens, M. J., Cornil, C. A., and Balthazart, J. (2011). Acute stress differentially affects aromatase activity in specific brain nuclei of adult male and female quail. Endocrinology. doi: 10.1210/en.2011-1341. [Epub ahead of print].

Doi, O., Takai, T., Nakamura, T., and Tanabe, Y. (1980). Changes in the pituitary and plasma LH, plasma and follicular progesterone, and estradiol, and plasma testosterone and estrone concentrations during the ovulatory cycle of the quail (Coturnix coturnix japonica). Gen. Comp. Endocrinol. 41, 156-163.

Foidart, A., De Clerck, A., Harada, N., and Balthazart, J. (1994a). Aromatase-immunoreactive cells in the quail brain: effects of testosterone and sex dimorphism. Physiol. Behav. 55, 453-464.

Foidart, A., Harada, N., and Balthazart, J. (1994b). Effects of steroidal and non steroidal aromatase inhibitors on sexual behavior and aromataseimmunoreactive cells and fibers in the quail brain. Brain Res. 657, 105-123.

Foidart, A., Reid, J., Absil, P., Yoshimura, N., Harada, N., and Balthazart, J. (1995). Critical re-examination of the distribution of aromataseimmunoreactive cells in the quail forebrain using antibodies raised against human placental aromatase and against the recombinant quail, mouse or human enzyme. J. Chem. Neuroanat. 8, 267-282.

Goy, R. W., and McEwen, B. S. (1980). Sexual Differentiation of the Brain.
Cambridge, MA: The MIT Press, 1-223.

Hammond, G. L. (1995). Potential functions of plasma steroid-binding proteins. Trends Endocrinol. Metab. 6, 298-304.

Harada, N., Abe-Dohmae, S., Loeffen, R., Foidart, A., and Balthazart, J. (1993). Synergism between androgens and estrogens in the induction of aromatase and its messenger RNA in the brain. Brain Res. 622, 243-256.

Harada, N., Yamada, K., Foidart, A. and Balthazart, J. (1992). Regulation of aromatase cytochrome P-450 (estrogen synthetase) transcripts in the quail brain by testosterone. Mol. Brain Res. 15, 19-26.

Hutchison, J. B., and Steimer, T. H. (1986). Formation of behaviorally effective 17beta-estradiol in the dove brain: steroid control of preoptic aromatase. Endocrinology 118 2180-2187.

Konkle, A. T., and Balthazart, J. (2011). Sex differences in the rapid control of aromatase activity in the quail preoptic area. J. Neuroendocrinol. 23, 424-434.

Kow, L.-M., and Pfaff, D. W. (2004). The membrane actions of estrogens can potentiate their lordosis behavior-facilitating genomic actions. Proc. Natl. Acad. Sci. U.S.A. 101, 12354-12357.

Maney, D., and Pinaud, R. (2011). Estradiol-dependent modulation of auditory processing and selectivity in songbirds. Front. Neuroendocrinol. 32, 287-302.

McEwen, B. S. (1981). Neural gonadal steroid actions. Science 211, 1303-1311.

Naftolin, F., Ryan, K. J., Davies, I. J., Reddy, V. V., Flores, F., Petro, Z., Kuhn, M., White, R. J., Takaoka, Y., and Wolin, L. (1975). The formation of estrogens by central neuroendocrine tissues. Rec. Prog. Horm. Res. 31, 295-319.

Naftolin, F., Ryan, K. J., and Petro, Z. (1972). Aromatization of androstenedione by the anterior hypothalamus of adult male and female rats. Endocrinology 90 , 295-298.

Nestler, E. J., and Greengard, P. (1999). "Serine and threonine phosphorylation," in Basic Neurochemistry. Molecular, Cellular and Medical Aspects, 6th Edn, eds G. J. Siegel, B. W. Agranoff, R. W. Albers, S. K. Fisher, and M. D. Uhler (Philadelphia: Lippincott-Raven), 471-495.

O’Malley, B. W., and Tsai, M.-J. (1992). Molecular pathways of steroid receptor action. Biol. Reprod. 46, 163-167.

Palkovits, M., and Brownstein, M. J. (1983). "Microdissection of brain areas by the punch technique," in Brain Microdissection Techniques, ed. A. C. Cuello (New York: Wiley), $1-36$.

Panzica, G. C., Viglietti-Panzica, C., and Balthazart, J. (1996). The sexually dimorphic medial preoptic nucleus of quail: a key brain area mediating steroid action on male sexual behavior. Front. Neuroendocrinol. 17, 51-125.

Panzica, G. C., Viglietti-Panzica, C., Calcagni, M., Anselmetti, G. C., Schumacher, M., and Balthazart, J. (1987). Sexual differentiation and hormonal control of the sexually dimorphic preoptic medial nucleus in quail. Brain Res. 416, 59-68.

Peterson, R. S., Yarram, L., Schlinger, B. A., and Saldanha, C. J. (2005). Aromatase is pre-synaptic and sexually dimorphic in the adult zebra finch brain. Proc. Biol. Sci. 272, 2089-2096.

Remage-Healey, L., and Bass, A. H. (2006). A rapid neuromodulatory role for steroid hormones in the control of reproductive behavior. Brain Res. 1126, 27-35.

Remage-Healey, L., Coleman, M. J., Oyama, R. K., and Schlinger, B. A. (2010). Brain estrogens rapidly strengthen auditory encoding and guide song preference in a songbird. Proc. Natl. Acad. Sci. U.S.A. 107, 3852-3857.

Remage-Healey, L., Maidment, N. T., and Schlinger, B. A. (2008). Forebrain steroid levels fluctuate rapidly during social interactions. Nat. Neurosci. 11, 1327-1334.

Rohmann, K. N., Schlinger, B. A., and Saldanha, C. J. (2007). Subcellular compartmentalization of aromatase is sexually dimorphic in the adult zebra finch brain. Dev. Neurobiol. 67, $1-9$.

Roselli, C. E. (1991). Synergistic induction of aromatase activity in the rat brain by estradiol and 5alpha-dihydrotestosterone. Neuroendocrinology 53, 79-84.

Roselli, C. E., Horton, L. E., and Resko, J. A. (1987). Time-course and steroid specificity of aromatase induction in rat hypothalamus-preoptic area. Biol. Reprod. 37, 628-633.

Roselli, C. E., Larkin, K., Resko, J. A., Stellflug, J. N., and Stormshak, F. (2004). The volume of a sexually dimorphic nucleus in the ovine medial preoptic area/anterior hypothalamus varies with sexual partner preference. Endocrinology 145, 478-483.

Roselli, C. E., and Resko, J. A. (1984). Androgens regulate brain aromatase activity in adult male rats through a receptor mechanism. Endocrinology 114, 2183-2189. 
Roselli, C. E., and Resko, J. A. (1989). Testosterone regulates aromatase activity in discrete brain areas of male rhesus macaques. Biol. Reprod. 40, 929-934.

Saldanha, C. J., Remage-Healey, L., and Schlinger, B. A. (2011). Synaptocrine signaling: steroid synthesis and action at the synapse. Endocr. Rev. 32, 532-549.

Schumacher, M., Alexandre, C., and Balthazart, J. (1987). Interactions des androgènes et des oestrogènes dans le contrôle de la reproduction. C. R. Acad. Sci. III 305, 569-574.

Schumacher, M., and Balthazart, J. (1983). The effects of testosterone and its metabolites on sexual behavior and morphology in male and female Japanese quail. Physiol. Behav. 30, 335-339.

Schumacher, M., and Balthazart, J. (1986). Testosterone-induced brain aromatase is sexually dimorphic. Brain Res. 370, 285-293.

Schumacher, M., and Balthazart, J. (1987). Neuroanatomical distribution of testosterone metabolizing enzymes in the Japanese quail. Brain Res. 422, 137-148.
Smith, C. L., and O'Malley, B. W. (2004). Coregulator function: a key to understanding tissue specificity of selective receptor modulators. Endocr. Rev. 25, 45-71.

Steimer, T., and Hutchison, J. B. (1981), Androgen increases formation of behaviourally effective oestrogen in dove brain. Nature 292, 345-347.

Taziaux, M., Keller, M., Bakker, J., and Balthazart, J. (2007). Sexual behavior activity tracks rapid changes in brain estrogen concentrations. $J$. Neurosci. 27, 6563-6572.

Tetel, M. J., Auger, A. P., and Charlier, T. D. (2009). Who's in charge? Nuclear receptor coactivator and corepressor function in brain and behavior. Front. Neuroendocrinol. 30, 328-342.

Tremere, L. A., Jeong, J. K., and Pinaud, R. (2009). Estradiol shapes auditory processing in the adult brain by regulating inhibitory transmission and plasticity-associated gene expression. J. Neurosci. 29, 5949-5963.

Tremere, L. A., and Pinaud, R. (2011). Brain-generated estradiol drives long-term optimization of auditory coding to enhance the discrimination of communication signals. J. Neurosci. 31, 3271-3289.
Viglietti-Panzica, C., Panzica, G. C., Fiori, M. G., Calcagni, M., Anselmetti, G. C., and Balthazart, J. (1986). A sexually dimorphic nucleus in the quail preoptic area. Neurosci. Lett. 64, 129-134.

Voigt, C., Ball, G. F., and Balthazart, J. (2007). Neuroanatomical specificity of sex differences in expression of aromatase mRNA in the quail brain. J. Chem. Neuroanat. 33, 75-86.

Voigt, C., Ball, G. F., and Balthazart, J. (2009). Sex differences in the expression of sex steroid receptor mRNA in the quail brain. J. Neuroendocrinol. 21, 1045-1062.

Voigt, C., Ball, G. F., and Balthazart, J. (2011). Effects of sex steroids on aromatase mRNA expression in the male and female quail brain. Gen. Comp. Endocrinol. 170, 180-188.

Watson, J. T., and Adkins-Regan, E. (1989). Neuroanatomical localization of sex steroid-concentrating cells in the Japanese quail (Coturnix japonica): autoradiography with $[3 \mathrm{H}]$-testosterone, $[3 \mathrm{H}]$-estradiol, and $[3 \mathrm{H}]$-dihydrotestosterone. $\mathrm{Neu}$ roendocrinology 49, 51-64.

Yahr, P. (1979). Data and hypotheses in tales of dihydrotestosterone. Horm. Behav. 13, 92-96.
Conflict of Interest Statement: The authors declare that the research was conducted in the absence of any commercial or financial relationships that could be construed as a potential conflict of interest.

Received: 05 July 2011; paper pending published: 08 August 2011; accepted: 02 September 2011; published online: 29 September 2011.

Citation: Balthazart J, Charlier TD, Cornil CA, Dickens MJ, Harada N, Konkle ATM, Voigt $C$ and Ball GF (2011) Sex differences in brain aromatase activity: genomic and nongenomic controls. Front. Endocrin. 2:34. doi: 10.3389/fendo.2011.00034

This article was submitted to Frontiers in Neuroendocrine Science, a specialty of Frontiers in Endocrinology.

Copyright (c) 2011 Balthazart, Charlier, Cornil, Dickens, Harada, Konkle, Voigt and Ball. This is an open-access article subject to a non-exclusive license between the authors and Frontiers Media $S A$, which permits use, distribution and reproduction in other forums, provided the original authors and source are credited and other Frontiers conditions are complied with. 